\title{
2
}

\section{THE REFIGURATION OF SPACE, CIRCULATION, AND MOBILITY}

\author{
Martina Löw and Hubert Knoblauch
}

\section{Introduction: social changes are spatial changes}

"Re-Figuration of Spaces" is the title of our research consortium, which is designed to work for up to 12 years. When writing this text, the Collaborative Research Center (in German: "Sonderforschungsbereich") had only just started a year earlier, at a time when we could not have imagined what would ensue during the current corona crisis (which we will address in an afterword added during the editing of this article.) Any attempt to provide a semblance of empirical results would therefore be utterly premature at this point. We do not wish to start with a speculative catchline aimed at attracting public attention for the next two or three weeks. Rather, we prefer to sketch a notion of refiguration that can serve as a framework for a number of chapters within this volume. As this notion has already been outlined elsewhere in some detail (Knoblauch and Löw 2017; Knoblauch 2020; Knoblauch and Löw 2020a), our objective is to explain how it can be understood as a sensitizing concept for empirical inquiries on the current transformation of space not only for the contributions in this volume but also for future research relating to the consortium and its questions. With the notion of refiguration, we address the following questions: How do the current societal transformations and their ensuing conflicts, crises, and uncertainties affect the relationship between humans and spaces, their spatial practices, and the means they use to negotiate and construct spatial orders? How do changes in spatial practices and spatial formations transform society?

These questions presuppose some theoretical reflections on the social constitution and the communicative construction of space (see Löw 2016; Knoblauch 2020), of which we can only articulate the basic result: That space is the medium in which the transformation of any society or social change takes place. This holds even more true for contemporary society, which is characterized, on the one hand, 
by functional differentiation, a vertical hierarchical order, and a tendency towards homogeneity and which, on the other hand, is often in tension with heterogeneity, heterarchies, and flat networks. The idea of refiguration is taken to describe the conflictual dynamic between these poles underlying societal transformation.

In this very short introduction, rather than outlining the general relational theory of space, we (1) sketch the notion of refiguration as a model for recent societal development. In the second part (2), we strive to delineate the approach to the questions of social and spatial transformation in our collaborative research group. As the title of the chapter suggests, we wish (3) to specifically inquire about the effects of mediatization of space on circulation and mobility. As refiguration is a sensitive concept, it is formulated in an abstract manner, thus leaving sufficient "space" and openness for specifications, modifications, and differentiations by means of empirical research.

In empirical research, we start from the methodological premise that what is social always takes on spatial forms. As much as this view came to be shared in the aftermath of the "spatial turn," it neglects the fact that current social changes and their ensuing conflicts, crises, and increasing uncertainties pose a common problem, namely that these crises, conflicts, and uncertainties affect the relationship between humans and spaces, their spatial practices, and the means they use to negotiate and construct spatial orders. We claim that a common pattern can be found in these transformations and conflicts, which we designate refiguration.

\section{Refiguration}

By refiguration, we mean that the social order of present-day societies results from two conflicting spatial logics based on two different dominant spatial figurations. While the notion of figuration builds on Elias' (1982) analysis of both societal and subjective changes in the civilization process, we use the term logic here in the sense of Bourdieu (1990) as a structural principle resulting from practicalities of action. To us, this praxeology depends on the spatial relations of (knowledgeable) bodies acting, interacting, and communicating with each other. Space is generally understood as a relational arrangement of living beings and social goods in places.

As Mol and Law (1994) suggest, one can clearly distinguish such logics from one another. Yet, the contemporary refiguration of society seems to be driven by the differentiation of institutionalized, specialized systems and the homogenization and centralization of bounded container spaces, which is probably best exemplified by the modern nation state. The second logic is characterized by relationality and refers to figuration represented by fluidity, hybridization, and transgression, sometimes symbolized by the network model. An important example of this may be the network society as suggested by Castells (2000). He links the rise of digitalization to a concept of network as a set of interconnected nodes at which different threads cross.

The notion of refiguration does not follow the linear argument implied in many globalization theories purporting that (late or postmodern) network society 
follows modern national society. Instead, it underlines the (1) persistence of these two dominant figurations (which are, of course, complemented by other spatial figurations, such as places and tracks), (2) the dynamics of conflict resulting from and caused by these figurations, and (3) the new forms, figurations, and spatial orders that result from these dynamics and are so often ignored by modernists and postmodernists, globalists and nationalists, structuralists and poststructuralists, and, more recently, unilateralists and multilateralists.

When addressing these encompassing dynamics, we refer to what Couldry and Hepp $(2017,57)$ call a figuration of figurations; that is to say, a model of society that covers the various orders within society. Changes in these figurations of figurations correspond to what Krotz (2001) has labeled a "megatrend.” By refiguration, however, we want to avoid the implied container metaphor, which is still implicit in Elias' notion of the encapsulation of figuration.

As mentioned earlier, we understand refiguration as a process, which is caused and driven by the dynamics of conflict resulting from the spatial tension between dominant figurations and spatial logics. In order to understand the conflictual dynamics, we can juxtapose certain features within each figuration in an exaggerated, characteristic manner as follows:

This conceptual opposition is simply a way to grasp the dynamics of refiguration in a tentative and hypothetical manner, which should not be misunderstood as propagating refiguration to be a desirable state. Rather, we presume that the two figurations serve as a reasonable basis for studying empirical differences, similarities, and changes in socio-spatial forms, which make it possible to explain the reasons behind the social crises and subjective uncertainties we have been witnessing over the last decades. There is a quite conflict-laden polarity between the tendency towards transnationalization, for example in the European Union, and the emphasis on territorial borders in modern nation states, between the ethnic or cultural conceptions of purity (for example, in Poland) and multi-ethnicity or multiculturalism (for example, in France), and between the national rejection of regional autonomy (in Spain) and the provision of autonomy (for example, in Great Britain).

$\begin{array}{lr}\text { Spatial compression } & \begin{array}{r}\text { Disembedding } \\ \text { Pentrality }\end{array} \\ \text { Hierarchy } & \text { Heterarchy } \\ \text { Nationalization } & \text { Transnationalization } \\ \text { Boundaries } & \text { Transgression } \\ \text { Container } & \text { Relationality } \\ \text { Exclusion } & \text { Inclusion } \\ \text { Territory } & \text { Deterritorialization }\end{array}$

DIAGRAM 2.1 Conflicting figurations and spatial logics 
If we search for a recent example of the dynamics in the conflictual spatial figurations, the current corona crisis would seem to provide a natural experiment (which is elaborated in Knoblauch and Löw 2020b). In fact, the tension between territorial and network logics, between hierarchy and heterarchy, between limitation and delimitation, and between homogeneity and heterogeneity has been particularly acute during the corona crisis. Refiguration explains the simultaneity and tension of the corona crisis, which is essentially a global risk. Thus, it is quite remarkable that the global expansion has not been met with a global response, and even in Europe the national states have clearly overruled transnational cooperation. Instead, unilateral decisions to close the borders of national and even regional territories were made. Borders, for decades neither controlled nor fortified, were closed without prior notice or consultation between states, such as France and Germany. Not only have national territories been closed off, national citizens stranded outside their countries were quickly "brought home" in unprecedented "repatriation" actions.

This closure of territorial space is met with the opposing principle of mediating spaces by networks. Those who cannot meet face to face resort to video conferences. Those who cannot work in the office work at their newly established home office, and those who do not want to go out to eat order via an app and hope that the packages are as clean as the Internet. In the current hyper-compressed emergency order, digital space compensates for public presence, where music is played, groups meet, and games are played. But it also replaces the other functions of society: Universities are to be completely converted to digital communication, as is public administration. The home office allows the majority of other organizations to operate with digital communication technologies. Internet, emails, and the video conferences keep us in international circles, allowing us to launch initiatives, maintain bubbles of bounded communication networks, and establish new rituals.

The basic idea behind refiguration consists of the assumption of conflictual but interdependent dynamics between these different logics, or in a more metaphorical sense, refiguration denotes the forms resulting from the "energy" between these opposite poles of these two logics. Every logic is, of course, in itself heterogeneous. What was once called modern and what used to be called postmodern is in itself an array of different elements that can be investigated (in our case, by comparing different space studies). Moreover, Norbert Elias' idea of interdependencies allows us to add that these dynamics affect all social fields and society at all (micro, meso, and macro) levels, including the individual actors along with their knowledge, bodies, and emotions. We expect different expressions of refiguration in various societal spheres (i.e. economy, politics, arts, etc.) and levels (from the individual to an organization and cultural areas), as well as interdependencies between them. In addition, in non-Western societies, the lines of conflict may be quite different. Thus, in the "compressed modernity" of South Korea and likely China, we assume the refiguration to be driven by the conflict between a rapid process of economic and technological instrumentalism with its networked logic, on the one hand, and on the other by a familialism based on the container space model. Chang 
(2010) calls this "individualization without individualism," supporting a specific East Asian form of nationalism, the reinvention of traditional values and kinship structures. Different lines of conflict may also be found in Muslim countries or Hinduist India—where conflict has been linked to religion-or, of course, South America and Africa. While the concept of refiguration is sensitive to these varieties of modernity, in the context of Western thinking, it allows us to adjust the epochal diagnosis in theories of modernization, globalization, and late and postmodernity.

Refiguration differs from a dialectical relation in that we do not assume that the conflictual poles are substituted (as Marx' dialectical materialism suggests) but, rather, are only changed and adopt new spatial forms. If their extreme characteristics come into direct contact with each other, this leads to changes, connections, or conflicts. The empirical studies are tasked with identifying these new forms so as to deduce the specific form of refiguration.

\section{Refiguration of spaces}

While there seems to be little doubt in social science discourse about the transformation of temporal structures and the acceleration of lives, communication, or markets, space has received much less attention when it comes to the diagnosis of contemporary society. Starting from the assumption that any social action finds its expression in space, we use the notion of refiguration of space to stress that the most diverging ongoing processes result in new figurations of space, such as the synthesis of virtual and real space in teleconferencing. To put it differently: Space is the medium of transformation for contemporary society as much as time. Therefore, the analysis of space provides an integrative starting point for the analysis of the emerging patterns of society.

If we focus on spatiality by using the concept of refiguration of spaces, we can see that the process of globalization is in conflict with the centralized figuration of the nation state with its bounded territory, clearly defined by enlightened cartography (Schlögel 2011), and characterized by its increased centralization of power, the monopolization of violence, and the differentiation of social structures. However, differences in spatial logics do not necessarily only result in conflict; territorial spatial forms (such as designated zones, camps, colonies, etc.) may co-exist, interlock with, or spread out alongside/over/beneath more fluid and more explicitly relational spatial assemblages (networks, layers, clouds, trajectories, etc.).

In similar terms, the homogenization of modern spaces, their clear functional differentiation (for example, modern cities divided into functional areas) or their vertical hierarchical order (e.g., in administrative architecture) is in tension with the heterogeneity of hybrid spaces, third or non-places, heterotopias, and the flatness of heterarchical orders so much underlined by theories of late, second, or postmodernity. The homogenizing top-down planning of smart cities in the Global South or in Asia, for instance, contrasts with the logic of networking and fluidity in the so-called smart infrastructure in the same countries. Similarly, the transgressive tendencies of transnationalism, cosmopolitanism, and world culture with its new 
virtual military conflicts, as institutionalized in the European Union for example, are confronted with the reaffirmation of principles of re-nationalization, the return of modern wars, and forms of regionalization that explicitly try to avoid the forms of adaptation postmodern theories call "glocalization."

This refiguration of society is articulated in fights over the meaning of spaces, in imaginary models of security and risk, and in processes of closure and exclusion, such as the erection of new frontiers, such as those between the UK and the EU, between Mexico and the U.S., or even between France and Germany during the corona crisis. These conflicts result in unpredictability and a lack of security and orientation. The most obvious transformation consists in what came to be known as globalization, meaning the increase in interdependencies and connectivity, such as the worldwide explosion of mobility, including groups of refugees, the circulation of commodities, free trade agreements between Japan and the EU, technical procedures and technologies, and the corresponding political, military, and legal strategies of control. At the same time, we are faced by opposing anti-globalizing tendencies such as Brexit, the abandonment of free trade agreements by the U.S. government, and "only eat local products" movements.

\section{Translocalization, polycontexturalization, and mediatization}

Refiguration can be tentatively characterized by three sub-processes, which function as sensitizing concepts for empirical investigations. The most well known of these concepts is that of translocalization. In using translocalization as a sensitizing concept, we assume that different places are increasingly linked, simultaneously increasing the relevance of constructions of locality because places are no longer assumed to be self-evident. For example, in our project on public space in the social web (coordinated by Barbara Pfetsch and Annie Waldherr, Pfetsch et al. 2019), we observed that U.S. politics is an important topic in the Twittersphere in Jerusalem (more important than in Berlin). The strong connection to U.S. topics seems to be driven by the Anglo-American population in Jerusalem, reflecting translocal ties.

The concept of polycontexturalization expresses our assumption that space, circulation, networks, and places, for example, are being connected in a new way by what we call communicative action (Knoblauch 2020). In the course of performing these embodied actions, more and more spaces, and potentially new spaces, are affected (or themselves affect these actions) and become effective at the same time. Take, for example, the massive change in control rooms (e.g., for the surveillance of crowds or monitoring mobility infrastructures). Control rooms constitute a paradigmatic form of modernity to control not only populations but also technological, natural resources, and risks. Surprisingly, digitalization with its assumed tendency towards networking and decentralization has not led to a substitution of spatially centralized control rooms, but rather has fostered the rapid integration of very different functionalities, such as water resources, health services, traffic, and electricity. The integration of different infrastructures into one local center and into a single control room connects a series of different spatial and material infrastructures that are not only observed 
by a scopic regime of multiple monitors and screens but also become relevant in contexts of actions - which take on what we believe to be a polycontextural character. This polycontexturalization, however, is not just a postmodern transgression of space; it appears to contribute to the bounding of certain spaces, such as smart cities, and to help accentuate the differences between urban and rural areas, nations and cultural areas, in a way conforming to our definition of refiguration.

In addition to translocalization and polycontexturalization, there is another concept that represents a major pillar for our understanding of refiguration: mediatization. Mediatization refers to the ways media and technology affect embodied communicative action, the relations constituted by them, and thus spatial structure. Its relevance can be easily understood if one recalls the substantial social transformation from oral cultures to literal cultures - in terms of settlements (cities) or political order (central power) (Soja 2011). One should also keep in mind that printing provided large masses of people with written and visual information (including maps very early on) several hundred years before the advent of the industrial society in England. Moreover, the electrification of industrial mass products and production in the 19th century was preceded by the dissemination of the telegraph, which made it possible to separate the means of communication and transport in a way that noticeably affected the spatial order immensely. In contrast to earlier spatial transformations, the current refiguration of space is related to and driven by the recent digital mediatization, which at the same time is a communication medium (computer). Digitalization has not led to the despatialization of society, as many had expected. Yet, digital mediatization quite obviously affects space, social action, and spatial imagination, as indicated by the study of locative media, such as dating apps, investigated in another research project (coordinated by Ingo SchulzSchaeffer; Lettkemann and Schulz-Schaeffer, 2021). There is little doubt that late and postmodern visions, including the network society and its space of flows (see Castells 2015), have been countered by insights into the communicative power of the new media monopoles and their capacity to centralize information. These new communicative figurations are addressed by Couldry and Hepp (2017) as "deep mediatization." Digital media ubiquitously permeate the whole of society and increase interdependencies through their technical connectivity, extending processes of social communication locally by speeding up communication. Although digital mediatization quite clearly reshapes and substitutes the rather centralized and hierarchical order of mass media, it is not restricted to media communication. Being based on the revolutionary connection of information and communication technologies, digitalization is increasingly affecting every field of society.

It is not just the media system, as communication theorists assume, but all industries, technologies, and infrastructures that are refigured by digital mediatization. In the economy, for example, this becomes apparent in the production of commodities like 3D printing, their dissemination on the market, and their consumption (or combination of production and consumption, i.e. prosumption) in ways that have been labeled-somewhat one-sidedly_- "digital capitalism," because most industries are still strongly tied to materiality. 
However, mediatization also affects politics, sports, and, as we are currently seeing, science. By changing the relations between subjects as well as between subjects and objects, mediatization contributes to the refiguration of subjective aspects of space. Institutions as well as actors and subjectivities are being refigured, too: Research on the socialization of children suggests that while spatial environments were perceived as fairly homogenous in the past, they are now increasingly experienced as isolated pockets of space (Zeiher and Zeiher 1994). Instead of one coherent unity, space appears as an accumulation of multiple interconnected, networked spatial fragments. These shifts are associated sometimes with increasing acts of vandalism in public spaces and an affinity for extremist positions (Heitmeyer 1996), but also with the revitalization of inner-city areas, as today's youth are out and about the city carrying mobile devices rather than sitting at home in front of the television.

\section{Circulation and mobility}

Mediatization visibly affects mobility and, consequently, the process we call "circulation" in that it can enhance and accelerate the movement of people, objects, and their communication in space, or it can intensify communication across space. Circulation refers to the way in which mobility creates spatial order and disorder. By circulation, we mean the movement of people, goods, signs, and technology between different places. Circulation is not an unsystematic, free flow of entities, but rather proceeds along orderly institutional paths, organizational fields, and social infrastructures with reliable transition points and follow-up operations. For example, food retailing is still strongly embedded in a city's built urban environment, and the corona crisis has revealed how strongly food production and retailing still depend on material infrastructures such as logistics. Nevertheless, even industries closely bound to materiality such as food production and retailing are affected by mediatization due to the increase in online retailing or the use of digitalization to improve logistics, for instance, thus resulting in complex new spatial forms (Baur et al. 2020).

If one thinks about the role of circulation in the refiguration of spaces, one quickly gets the impression that spaces of circulation are a consequence of social transformations. A closer look, however, shows that these trajectories (predefined paths of circulation, lines, routes of traffic) in which circulations occur have always been a necessary component of the construction of modern-day spaces. Routes, lines, paths, and tracks of various kinds (such as rivers, railway lines, public transport networks, motorways, footpaths) are the underlying material structures that have a propensity towards mobility, in homogenously designed urban spaces, for example.

Taking Le Corbusier's urban utopias as case studies, it is possible to understand how the contemporary city was consistently divided into spatially distinct, formally and functionally differentiated zones, and how the trajectory was implicitly established as a new leading figure, initially in urban planning (Vinken 2008). 
Ulrike Jureit (2012) demonstrates in the context of the discovery of colonial space that this dynamic in modern society is not only visible in cities. Explorers, land surveyors, and adventurers followed clearly defined routes on foot or on horseback, with the clear intention of expanding the knowledge of space. In fact, the linearity of their routes transformed these paths into trajectorial space. The information gathered along the way flowed into a single map, with the spaces beyond the route remaining blank and thus perceived as empty space. The trajectorial space, which, in this case, is the precondition for the enforcement of territorial space, unfolds its pervasive logic of circulation, as postulated by Robert Venturi, Denise Scott Brown, and Steven Izenour (1977), in the form of the highway and automobile-driving subjects. It is evident in many newly founded cities outside Europe that an orientation towards roads, bicycle lanes, sidewalks, lanes for electric scooters, underground waste transportation systems, and information highways radically structures daily life.

The Korean city of Songdo, for example, which we are studying in various individual projects within the framework of our Collaborative Research Center (Löw and Stollmann 2018), stands out as a trajectorial space par excellence: With a target population of 70,000 (currently 35,000), the city boasts a number of eightlane streets, assorted sidewalks that are several meters wide, and numerous cycle paths (although hardly any Koreans ride a bicycle). The shopping mall in Songdo was designed by the architect Minsuk Cho so that it could be easily crossed with electric scooters. Garbage is transported underground on conveyor belts and processed centrally. All these paths, lines, tracks, and routes that facilitate circulation, mobility, and displacement have not yet been sufficiently factored in as significant spatial areas in their own right in relevant research and theories (with the possible exception of research in urban planning departments). It is, however, trajectorial space (which also includes shipping and air routes) that organizes social coexistence and societal relations at the most fundamental level. The spatial analysis of Twitter networks demonstrates, for example, that statements of solidarity after terrorist attacks are sent not primarily from the region or from neighboring cities, but rather from cities with the most effective and lowest-priced flight connections to the attacked city (Lin and Margolin 2014).

Trajectorial spaces of circulation are especially relevant to the understanding of refiguration, since they literally "pave the way" out of the spatial homogenization of modern spaces with their clear functional differentiation or vertical hierarchical order right from the start. For Rudolph Schwarz, the general planner in the reconstruction of Cologne (after its destruction in WWII), for example, the transport system was a means to connect the homely city (a concept of place) to the world (a concept of translocality by circulation and trajectorial space).

In the very way that we conceive refiguration of present-day societies to follow two dominant conflicting spatial logics of "container" and "network" simultaneously, which are interdependent, circulation linked to territoriality is both part of modernity and a precondition for digitalized mediatization and deterritorialization. This becomes even more complicated if we return to translocalization. 
Translocalization designates the linkage of different places. It does not necessarily mean the dislocation or even annihilation of place but instead can serve to boost the constructions of locality. From this perspective, places are simply no longer regarded as self-evident, and circulation forces us to develop an even stronger notion of place. We have to consider what is happening in Songdo and all over the world: If spaces of circulation and mobility become stronger, then we witness an increased emotional need to create spaces as networks of places (e.g., the reinvention of traditional Korean houses as meeting places and landmarks). Territorial spatial forms co-exist, interlock with, and spread out alongside, over, and beneath more fluid, more explicitly relational spatial networks, connections, and figurations. It is the very empirical task in our study of refiguration to answer the question: How do they do this? The forms of spaces (territorial space, trajectorial space, network space, etc.) are of interest for empirical spatial research, but the sociospatial aspect is best researched (in our opinion) with an emphasis on refiguration.

\section{Conclusion}

As mentioned at the beginning, the ideas presented here are not straitjackets but rather are considered sensitizing concepts. The refiguration of spaces, therefore, should be specified by means of the empirical studies conducted within the context of our collaborative research cluster as well as in neighboring research endeavors. The chapters in this volume constitute examples of such research. We also hope to learn from future research about the qualities and the range of the social transformations of space that we call refiguration.

\section{Acknowledgements}

This research has been funded by the Deutsche Forschungsgemeinschaft (DFG, German Research Foundation)—project number 290045248—SFB 1265.

\section{References}

Baur, Nina, Julia Fülling, Linda Hering, and Elmar Kulke, eds. 2020. Waren-WissenRaum. Interdependenz von Produktion, Markt und Konsum in Lebensmittelwarenketten. Wiesbaden: Springer VS.

Bourdieu, Pierre. 1990. The Logic of Practice. Stanford: Stanford University Press.

Castells, Manuel. 2000. The Rise of the Network Society. Oxford: Blackwell.

Castells, Manuel. 2015. Networks of Outrage and Hope: Social Movements in the Internet Age. Chichester: Wiley.

Chang, Kyung-Sup. 2010. "East Asia's Condensed Transition to Second Modernity." Soziale Welt 61 (3-4): 319-328. doi: 10.5771/0038-6073-2010-3-4-319.

Couldry, Nick, and Andreas Hepp. 2017. The Mediated Construction of Reality. London: Polity.

Elias, Norbert. (1939) 1982. The Civilizing Process, Vol. 2. Oxford: Blackwell.

Heitmeyer, Wilhelm. 1996. "Die gefährliche Zerstückelung von Zeit und Raum. Zu den Folgen wachsender sozialer Desintegration.” Frankfurter Rundschau, September 26: 18. 
Jureit, Ulrike. 2012. Das Ordnen von Räumen. Territorium und Lebensraum im 19. und 20. Jahrhundert. Hamburg: Hamburger Edition.

Knoblauch, Hubert. 2020. The Communicative Construction of Reality. London: Routledge.

Knoblauch, Hubert, and Martina Löw. 2017. "On the Spatial Re-Figuration of the Social World.” Sociologica 11 (2): 1-27. doi: 10.2383/88197.

Knoblauch, Hubert, and Martina Löw. 2020a. "The Re-Figuration of Spaces and Refigured Modernity-Concept and Diagnosis." Historical Social Research 45 (2): 263-292. doi: 10.12759/hsr.45.2020.2.263-292.

Knoblauch, Hubert, and Martina Löw. 2020b. "Dancing in Quarantine: The Spatial Refiguration of Society and the Interaction Orders." Space and Culture 23 (3): 221-225. doi: $10.1177 / 1206331220938627$.

Krotz, Friedrich. 2001. Die Mediatisierung kommunikativen Handelns. Der Wandel von Alltag und sozialen Beziehungen, Kultur und Gesellschaft durch die Medien. Wiesbaden: Westdeutscher Verlag.

Lettkemann, Eric, and Ingo Schulz-Schaeffer. 2021. "Lokative Medien: Inklusion und Exklusion in öffentlichen Räumen.” In Räume digitaler Kommunikation. LokalitätImagination - Virtualisierung, edited by Thomas Döbler, Christian Pentzold, and Christian Katzenbach, 72-103. Köln: Halem.

Lin, Yu-Ru, and Drew Margolin. 2014. "The Ripple of Fear, Sympathy and Solidarity during the Boston Bombings." EPJ Data Science 3. doi: 10.1140/epjds/s13688-014-0031-z.

Löw, Martina. 2016. The Sociology of Space. Materiality, Social Structures, and Action. New York: Palgrave Macmillan.

Löw, Martina, and Jörg Stollmann. 2018. "Urbanität in Smart-City-Entwürfen und Stadtvisionen? Moderne Stadtentwicklung zwischen Songdo und Limerick." In Urbanität im 21. Jahrhundert, edited by Norbert Gestring, and Jan Wehrheim, 336-343. Frankfurt am Main: Campus.

Mol, Annemarie, and John Law. 1994. "Regions, Networks and Fluids: Anaemia and Social Topology.” Social Studies of Science 24 (4): 641-671. doi: 10.1177/030631279402400402.

Pfetsch, Barbara, Daniel Maier, Daniela Stoltenberg, Annie Waldherr, Neta Kligler-Vilenchik, and Maya de Vries. 2019. "How Local is the Digital Public Sphere on Twitter? A Comparison between Jerusalem and Berlin." Paper presented at the 69th Annual Conference of the International Communication Association (ICA), Washington, DC, May 24-28.

Schlögel, Karl. 2011. Mastering Russian Spaces. Raum und Raumbewältigung als Probleme der russischen Geschichte. München: Oldenbourg.

Soja, Edward W. 2011. "Cities and States in Geohistory." Theory and Society 39 (3-4): 211226. doi: 10.1007/978-94-007-0756-6_15.

Venturi, Robert, Denise Scott Brown, and Steven Izenour. 1977. Learning from Las Vegas. The Forgotten Symbolism of Architectural Form. Cambridge, MA: MIT Press.

Vinken, Gerhard. 2008. "Ort und Bahn. Die Räume der modernen Stadt bei Le Corbusier und Rudolf Schwarz." In Räume der Stadt. Von der Antike bis heute, edited by Cornelia Jöchner, 147-164. Berlin: Reimer.

Zeiher, Hartmut J., and Helga Zeiher. 1994. Orte und Zeiten der Kinder. Soziales Leben im Alltag von Großstadtkindern. Weinheim: Juventa. 